\title{
Morphology of the bone marrow, spleen and liver during hematopoietic cell mobilization with cyclophosphamide in mice
}

\author{
Kamila Barcew1, Anna Karbicka1, Pawel Szumilas', Mariola Marchlewicz², \\ Ryszard Grzegrzółka1, Barbara Wiszniewska ${ }^{2}$, Bogusław Machaliński ${ }^{1}$ \\ ${ }^{1}$ Departament of General Pathology, Pomeranian Medical University \\ ${ }^{2}$ Department of Histology and Embryology Pomeranian Medical University, Szczecin, Poland
}

\begin{abstract}
Cyclophosphamide (CY), the agent with cytoreductive activity, is widely exploited in cancer chemotherapy, and can be used alone or in combination with various cytokines and growth factors to stimulate the egress of hematopoietic stem/progenitor cells (HSPC) from the BM compartment. The aim of the present study was to exam the morphology and ultrastructure of the bone marrow, spleen and liver of mice injected intraperitoneally with a single dose of cyclophosphamide $(200 \mathrm{mg} / \mathrm{kg} \mathrm{bw})$ and the localization of cells expressing markers of early hematopoietic cells in studied organs and the peripheral blood. We observed that the CY-induced morphological changes in the BM and spleen were reconstructed on day 4. of experiment, and the spleen was repopulated by HSPC on the $6^{\text {th }}$ day. In this time, the highest number of c-Kit-R-positive cells was determined by flow cytometry in the peripheral blood. The results confirmed, that the egress of HSPC from the bone marrow into the peripheral blood was delayed compared to mice treated with G-CSF or GCS-F plus CY.
\end{abstract}

Key words: Balb-C mice, bone marrow, cytoreductive drug, immunohistochemistry, liver, spleen

\section{Introduction}

Hematopoietic stem and progenitor cells (HSPC) normally reside in the bone marrow $(\mathrm{BM})$, however in physiological conditions, very low number of early hematopoietic stem cells circulate in the peripheral blood. The number of the cells in blood can increase during pharmacologic mobilization, which has been shown to be induced clinically or experimentally in animal models by a wide number of molecules including cytoreductive drugs, such as cyclophosphamide (CY) $[1,2]$. Cyclophosphamide, a DNA alkylating agent, is widely exploited in cancer chemotherapy. However, this cytoreductive chemotherapeutic agent can be used alone or in combination, mainly with GCSF, to mobilize HSPC from the BM compartment. Both CY and G-CSF induce the expansion of neutrophils and their progenitors within the BM [3]. The mechanism of HSPC mobilization with chemothera-

Correspondence: B. Machalinski, Dept. of General Pathology, Pomeranian Medical University, Al. Powtancow Wlkp. 72, 70-111 Szczecin, Poland; tel.: (+4891) 4661546, fax.: (+4891) 4661548, e-mail: machalin@sci.pam.szczecin.pl peutic alone or in combination with e.g. G-CSF induces accumulation of proteases released from neutrophils into the extravascular compartment of BM. These proteases degrade and inactivate adhesive and chemotactic interactions between HSPC and the BM stromal cells, particularly VCAM-1, CXCR4 and its ligand SDF-1, decreasing affinity of CXCR4/SDF-1 axis [3-7]. A pivotal role in the mobilization of HSPC is attributed to complement system and egress of HSPC from the BM is thought as a part of an immune response [8].

Nevertheless, the morphology of the bone marrow and organs which could be repopulated by mobilized HSPC is poor known. In our previous studies we observed in mice morphological changes in organs participating in hematopoiesis during mobilization with G-CSF alone and G-CSF plus CY [9-11]. Our preliminary study had shown drastic changes in BM morphology on the $2^{\text {nd }}$ day after single injection of CY and the changes were maintained until the 4th day of experiment [12]. The aim of the present study was to show the morphology and ultrastructure of the bone marrow, spleen and liver of mice after one-off administration of cyclophosphamide as well as the localiza- 
tion of cells expressing markers of early hematopoietic cells in studied organs.

\section{Material and methods}

Mice. The experiment was performed on pathogen-free, 5-weekold, mature female inbred Balb $\mathrm{C}$ mice (Polish Academy of Sciences, Wroclaw, Poland). The animals were maintained under standard laboratory conditions in a $12 \mathrm{hr} / 12 \mathrm{hr}$ light-dark cycle at $21^{\circ} \mathrm{C}$. An approval from Local Ethical Committee was obtained. The animals were randomly divided into control and experimental groups (10 animals in each group). The mice of experimental group were injected intraperitoneally with single dose $(200 \mathrm{mg} / \mathrm{kg}$ bw) of cyclophosphamide (Endoxan, Asta Medica) on the day 0. of the experiment. Cyclophosphamide (CY) was diluted in solution of saline, according to the manufacture's recommendation. The mice of control group were injected intraperitoneally with a phosphatebuffered saline (PBS) on the day 0 in the same volume as the cyclophosphamide in experimental group. The experiment was terminated after 6 days. The mice of control and experimental groups were sacrificed by lethal anesthesia with $90 \mathrm{mg} / \mathrm{kg}$ bw thiopental (Biochemie GmbH, Kundl, Austria) after 2, 4 and 6 days of the experiment. Fragments of spleen and liver were collected and fixed with Carnoy'a solution [13]. Femurs were decalcified and embedded in paraffin. For morphological studies, the slides were stained with H-E, H+E slides of liver with PAS method, and additionally the silver impregnated method was used to visualize of reticular fibers in the spleen [13]. Pieces of spleen and liver for immunostaining were fixed in $4 \%$ formaldehyde freshly prepared from paraformaldehyde and embedded in paraffin.

Transmission electron microscopy [TEM]. For electron microscopic studies, the bone marrow of control and experimental mice was obtained (flushed from the femurs) using syringe and Iscove's medium. Bone marrows were fixed in $0.25 \mathrm{M}$ glutaraldehyde in 0.1 $\mathrm{M}$ cacodylate buffer $\mathrm{pH}=7.4$ for $2 \mathrm{hr}$ at $4^{\circ} \mathrm{C}$, post-fixed in $0.04 \mathrm{M}$ $\mathrm{OsO}_{4}$, and dehydrated in ethyl alcohol (30-96\%) and 100\% acetone, subsequently embedded in a Spurr low-viscosity embedding kit (Polysciences, Inc. Warrington, PA). Ultrathin sections were prepared with Reichert OmU2 ultramicrotome, contrasted with uranyl acetate and lead citrate, and analyzed in a JEM-1200 EX transmission electron microscope at $80 \mathrm{kV}$.

Immunohistochemical staining. Immunohistochemical reactions for identification of early hematopoietic stem cells in specimens of bone marrow, spleen and liver were performed using following antibodies:

- rabbit polyclonal anti-Thy-1 (H-110) (Santa Cruz Biotechnology, Inc., USA); - antibody raised against recombinant protein corresponding to amino acids $20-130$ representing the mature Thy-1 of human origin. Thy-1 (H-110) reacts with Thy-1 of mouse, rat and human origin.

- rabbit polyclonal anti-c-Kit (C-19) (Santa Cruz Biotechnology, Inc., USA) - antibody against peptide mapping within the carboxy terminal domain of c-Kit p145 of human origin. The ligand for c-Kit receptor has been identified and shown to be encoded at the murine steel (SI) locus.

Briefly, specimens were cut in $5 \mu \mathrm{m}$ sections, mounted on poly-L-lysine-coated microscope slides, deparaffinized, rinsed with graded alcohol, and washed with water. To reduce non-specific staining, the slides were immersed in $3 \%$ hydrogen peroxide for $30 \mathrm{~min}$ at room temperature to quench endogenous peroxidase activity. After washing in Tris-buffered saline (TBS) twice for 5 min, sections were submerged in $10 \mathrm{nM}$ citric buffer, $\mathrm{pH}=6.0$, and microwaved at high power two times for 5 min each time. Slides were then left to cool to room temperature in the buffer solution (20 min). Slides were washed again in TBS twice for $5 \mathrm{~min}$, and non-specific binding was blocked by incubation with 3\% normal goat serum for $30 \mathrm{~min}$ at room temperature followed by incubation with primary antibodies: anti-Thy-1 antibody (1:500) or anti-c-Kit$\mathrm{R}$ antibody $(1: 200)$ for the time recommended in the manufacturer $\mathrm{s}$ protocol at $22^{\circ} \mathrm{C}$. Slides were subsequently washed twice with TBS for $5 \mathrm{~min}$ and incubated with biotinylated antirabbit/mouse/goat immunoglobulins [(LSAB+AP Link, Universal, DAKO, Carpinteria, USA]. Sections were washed in TBS and incubated for 30 min with streptovidin conjugated to alkaline phosphatase (AP) (DAKO, Corporation, Carpinteria, USA). Sites indicating antibody binding were visualized using Fuchsin+chromogen (DAKO LSAB ${ }^{\circledR}+$ SYSTEM, AP) and fuchsia-coloured end product was obtained. Sections were washed in TBS and incubated counterstained with Mayer hematoxylin. Control slides were incubated without the primary antibody.

Flow cytometry. On the days 2, 4, and 6 after CY injection peripheral blood was obtained in each case from vena cava (with a 25guage needle and $1 \mathrm{~mL}$ syringe containing $250 \mathrm{U}$ heparin) and enriched for light-density mononuclear cells as described previously [14]. To determine the amount of c-Kit-R-positive cells, flow cytometric analysis was performed. Briefly, $50 \mu \mathrm{L}$ whole blood was stained with rat anti-mouse c-Kit-R fluorescein isothiocyanate (FITC)-conjugated monoclonal antibody (final concentration 1 $\mu \mathrm{g} / \mathrm{mL}$; BD Biosciences Pharmingen, San Diego, CA, USA). Samples stained with appropriate isotype controls (BD Biosciences Pharmingen) were also examined. After 20-min incubation on ice, $2 \mathrm{~mL}$ of FACS lysing solution (BD Biosciences Immunocytometry System, USA) was added to lyse the erythrocytes. The cells were washed twice in PBS, resuspended in $0.3 \mathrm{~mL}$ PBS, and analyzed by FACScan using CELLQUEST v.3.1 software (BD Biosciences Immunocytometry System, USA). Typically, 20000 events were acquired and the percentage of c-Kit-R-positive cells were determined for the whole leukocyte population.

Statistical analysis. Arithmetic mean and the standard deviation (mean \pm SD) data were determined using the STATGRAPHICS v.5.0. package (Manugistic Inc., Rockville, MD, USA). Statistical significance was defined as $\mathrm{P}<0.05$. Data were analysed using Student's t-test for unpaired samples.

\section{Results}

\section{Bone marrow morphology during hematopoietic cell mobilization with $C Y$ in mice}

Control mice. As it was presented in our former study [12], in the bone marrow of control mice hematopoietic cells arranged in hematopoietic cords were observed. Among the hematopoietic cells megakaryocytes with an irregularly lobulated nucleus were spread. The lumen of sinusoidal capillaries was filled with single leukocytes. Adipose cells were not visible (Fig. 1A).

Experimental group of mice. After two days of mobilization with $\mathrm{CY}$, the structure of the bone marrow was severely damaged. The vascular compartment of bone marrow with dilated sinusoids filled with erytrocytes dominated over the hematopoietic compartment. There were only little islets of hematopoietic cells. Megakaryocytes and erythrocytes outside capillaries were seen among hematopoietic cells. Few cells containing hemosiderin were visible in hematopoietic compartment (Fig. 1B). 

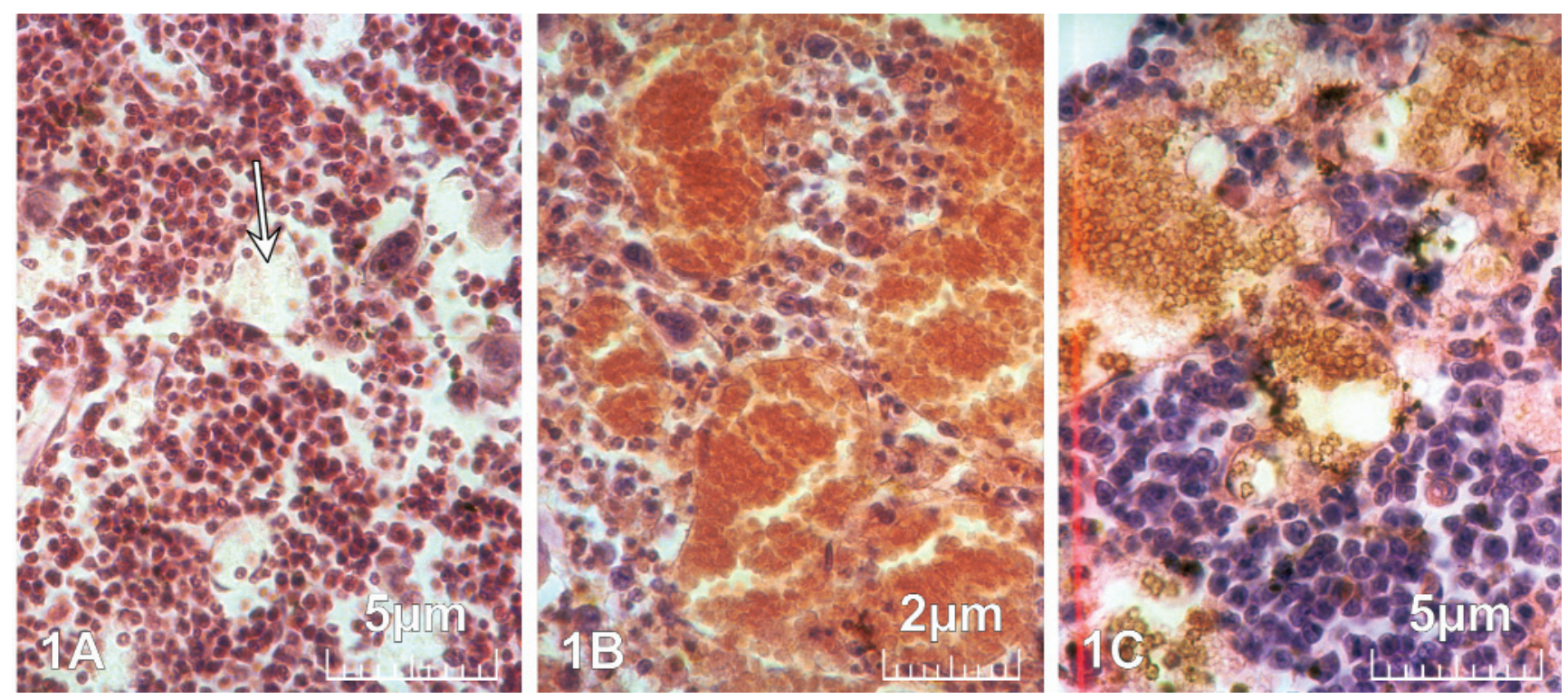

Fig. 1. The bone marrow of control (A) and CY-mobilized mice (B, C). The strong dilated sinusoids filled with erythrocytes, and the presence the erythrocytes among cells of small areas of hematopoietic compartment in BM after 2 days of experiment (B). The increase in hematopoietic cells number with the proliferating cells, and cells with hemosiderin, both in hematopoietic and vascular compartments on the 4th day $(\mathrm{C}) \mathrm{H}+\mathrm{E}$.

After 4 days of mobilization with CY, the sinusoids of the bone marrow were distinctly dilated but the area occupied by hematopoietic cells increased and numerous proliferating cells were observed within the hematopoietic compartment. There were numerous hemosiderin granules within both hematopoietic and vascular compartments (Fig. 1C).

After 6 days of mobilization with CY the morphology of the BM was similar to that observed in control mice. However, the amount of hematopoieic cells was increased and proliferating cells were visible. The lumens of sinusoid were still insignificantly dilated and single leucocytes were inside present.

\section{The ultrastructure of the bone marrow}

The BM ultrastructure of control mice was the same as that observed in mice stimulated with G-CSF [10] and G-CSF plus CY [11]. Briefly, sinusoids of the BM presented a normal structure. The wall of capillaries was composed of a single layer of fenestrated endothelial cells resting on the discontinuous basal lamina (not shown).

After day 2. of mobilization with CY the structure of the bone marrow was damaged and signs of fibrosis were observed. Numerous collagen fibers were accumulated in the stroma (Fig. 2A).

After 4 days of the experiment ultrastructure of the bone marrow was formerly changed. Beside of increased number of hematopoietic cells, the features of fibrosis were still observed. However, the amount of collagen fibers decreased (Fig. 2B).
After 6 days of mobilization with CY the ultrastructure of the bone marrow approximated the tissue of control mice. However, evidently wide spaces between the endothelial cells of sinusoids and cells traversing the endothelial wall were visible, similar to those visible in the BM of mice stimulated with GCSF plus CY [11].

\section{Immunolocalization of early hematopoietic cells in the bone marrow of control mice}

The colored product of immunohistochemical reaction was found in the cytoplasm of the BM cells. There was no reaction in the nuclei of the cells. The localization of cells that were identified with two different antibodies (anti-c-Kit-R and anti-Thy-1) in other slides, was the same. Few cells displayed c-kit-R- or Thy-1positive reaction among hematopoietic cells.

\section{Spleen morphology during hematopoietic cell mobilization with cyclophosphamide in mice}

Control mice. Splenic pulp of control mice was composed of white pulp and red pulp. White pulp consisted of lymphoid nodules with the central artery located eccentrically. Lymphoid nodules appeared within the red pulp were surrounded with well visible marginal zone (Fig. 3A). Red pulp was composed of elongated splenic cords and sinusoids lying between cells of the splenic cord. Megakaryocytes with an irregularly lobulated nucleus were visible among the cells of red pulp. 

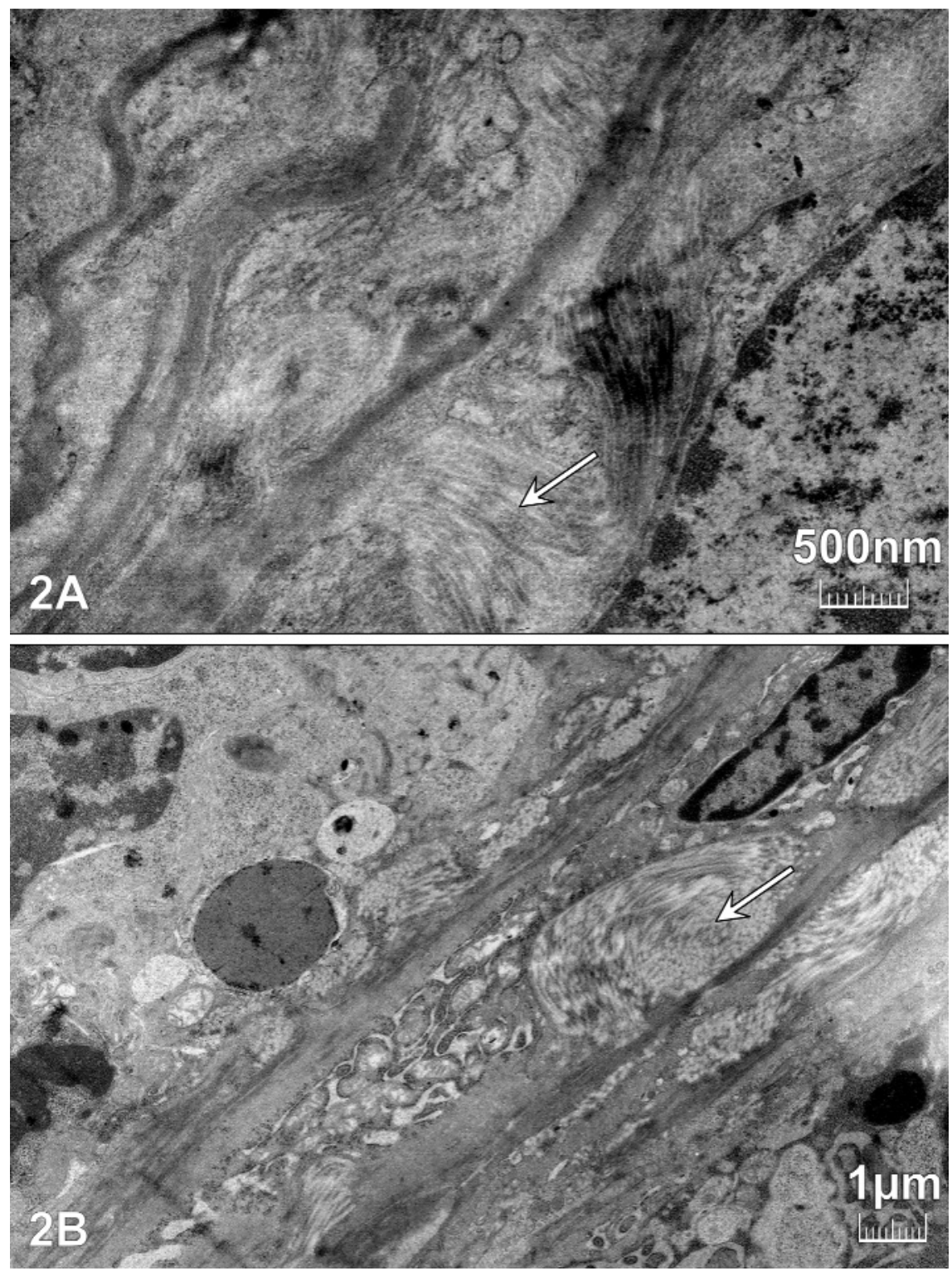

Fig. 2. Ultrastructure of the bone marrow of mice mobilized with CY. Symptoms of fibrosis with deposits of collagen fibers (arrow) in the $\mathrm{BM}$ on the $2^{\text {nd }}(\mathbf{A})$ and $4^{\text {th }}(\mathbf{B})$ days. TEM.
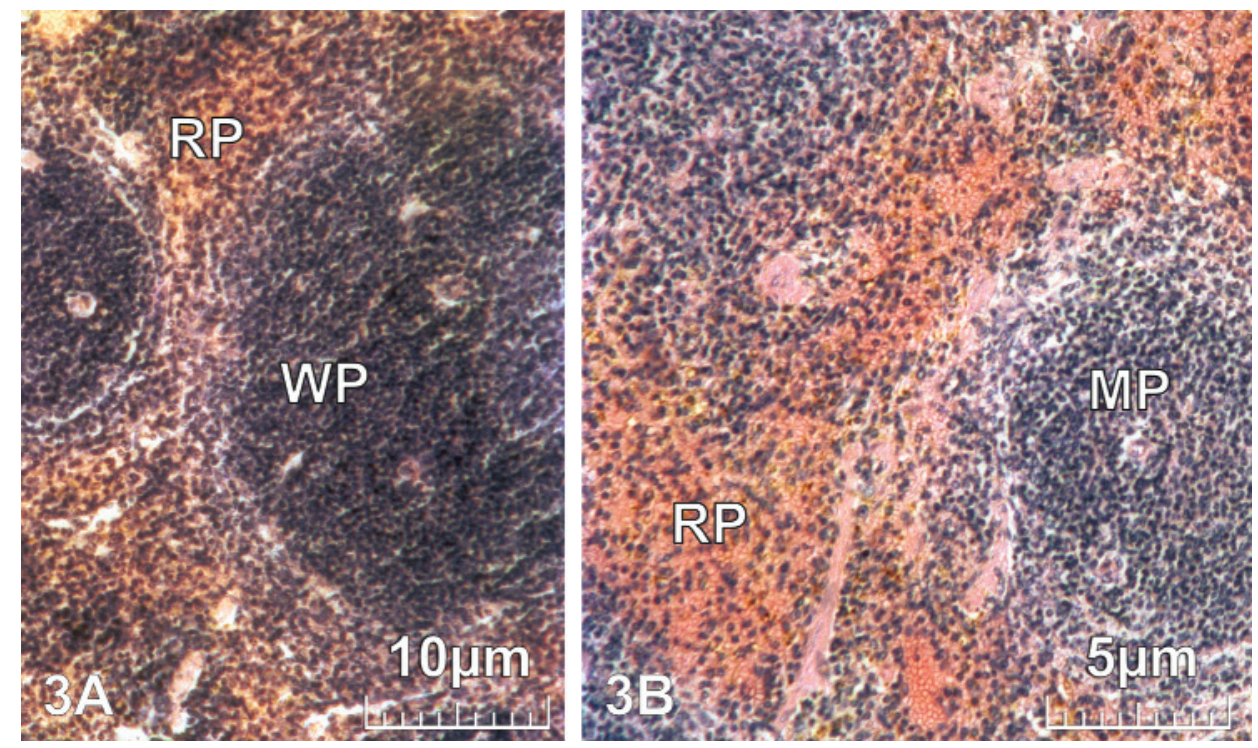

Fig. 3. Morphology of spleen in control mice and after CY mobilization. The white pulp (WP) and the red pulp (RP) in spleen of control mice (A), and domination of RP over WP in the spleen of mice on the $2^{\text {nd }}$ day of experiment $\mathrm{H}+\mathrm{E}$. 

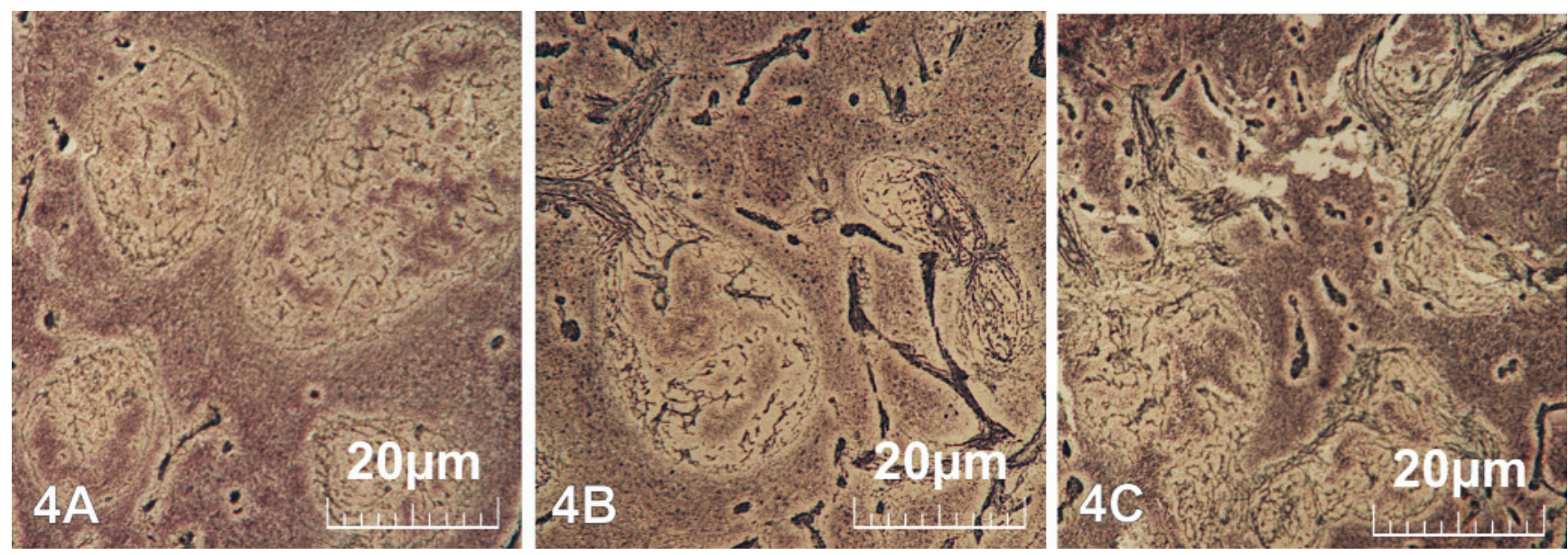

Fig. 4. Distribution of reticular fibers in the spleen of control mice $(\mathbf{A})$ and mice on $2^{\text {nd }}(\mathbf{B})$ and $4^{\text {th }}(\mathbf{C})$ day after CY treatment.

Experimental group of mice. On the $2^{\text {nd }}$ day after injection of mice with $\mathrm{CY}$, the spleen displayed increase in red pulp area over white pulp and decrease in size of lymphoid nodules. The marginal zone around lymphoid nodules and splenic cords in the red pulp were poorly visible. Sinusoids were filled with erytrocytes. There were megakaryocytes with strongly stained nuclei. Single cells with granules of hemosiderin were observed (Fig. 3B).

In macroscopic observation, the size of spleen in mice on the day 4. of experiment was significantly lower than the size of control mice spleen. The farther continuation decrease in volume of white pulp was observed. The lumen of trabecular vessels was considerably dilated and filled mainly with erytrocytes. Single megakaryocytes and numerous cells with hemosiderin granules were visible in red pulp.

The morphology of spleen in mice after the day 6 . since the injection with $\mathrm{CY}$ was similar to that observed in control mice. However, the lumen of parenchymal vessels was insignificantly dilated and filled with numerous of leukocytes.

\section{The visualization of reticular fibers}

After silver impregnation of specimens of spleen in control mice, the network of reticular fibers was visible (Fig. 4A). A prominent densification of reticular fibers was observed on the $2^{\text {nd }}$ and $4^{\text {th }}$ day of experiment (Fig. 4B,C), while the reticular network in spleen in the experimental mice on day 6 seemed to be similar to the control.

\section{Immunolocalization of early hematopoietic cells in spleen}

The identification of early hematopoietic cells in spleen of control and experimental groups of mice were carried out with two different antibodies but the localization of stained cells was the same for both antibodies. The product of immunohistochemical reactions was seen only in the cytoplasm of cells. In the spleen of control group of mice single Thy-1- or c-Kit-R-positive were present within the white pulp and red pulp (Fig. 5A). The increase in number of immunopositive cells was found in spleen of mice on the 6. day of the experiment. The cells were located both in white and red pulp of spleen (Fig. 5B).

\section{Liver morphology during hematopoietic cell mobilization with $C Y$ in mice}

Control mice. The classic liver lobules were not markedly separated from each other by connective tissue. At the corner of the lobules the portal spaces were present, occupied by the portal vein, the hepatic artery and the bile duct as well as small amount of connective tissue. Hepatocytes were grouped in interconnected plates. The radial dispositions of the plates forming a layer one or two cell thick layer were visible in the lobule. These plates were directed from periphery of the lobule to its center where the centrolobular vein was present. The plates of hepatocytes were separated by sinusoidal capillaries. In the lumen of the sinusoid the nuclei of Kupffer cells were seen. The cytoplasm of hepatocytes stained with $\mathrm{H}-\mathrm{E}$ was eosinophilic and contained one or two nuclei with granular chromatin (not shown).

Experimental group of mice. There were no distinct changes in morphology of liver of experimental group of mice. However, on the day 6 . of the experiment the increase of lymphoid tissue elements and number of Kupffer cells were observed (not shown). 

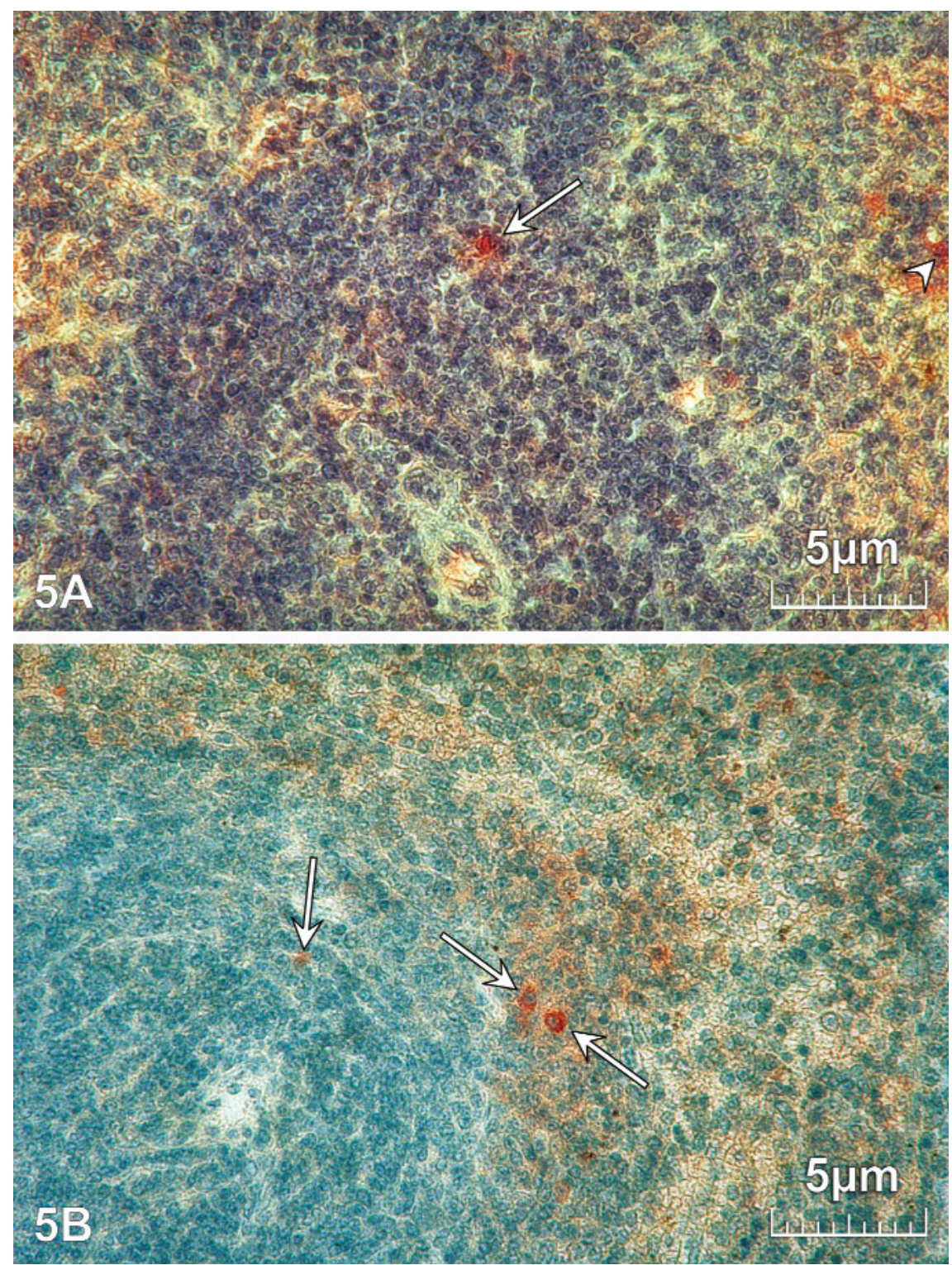

Fig. 5. Immunolocalization of c-Kit-R-positive cells in the spleen. The individual immunopositive cells in the spleen of control mice (arrow) (A) and numerous cells with immunostaining in spleen of mice on the $4^{\text {th }}$ and $6^{\text {th }}$ day after CY treatment.

\section{Immunolocalization of Thy-1- or c-Kit-R-positive cells in liver}

Three types of cells showing Thy-1 or c-Kit-R expression were observed in liver of control and experimental group of mice. There were small cells located in portal space as well as among hepatocytes and cells resemble two nuclei hepatocytes. These data are in accordance with those observed in our previous study [11].

\section{Percentage of c-Kit-R-positive cells in peripher- al blood}

We found the increase in number of circulating c-KitR-positive cells with peak number on day 6 of the experiment (Fig. 6). However, this increase was statistically insignificant.

\section{Discussion}

Hematopoietic stem and progenitor cells (HSPC) normally reside in the BM. They are confined to the bone marrow niches, proliferate and following differentiation, as mature blood cells migrate into the circulation. However, small pool of primitive stem cells continuously circulates in blood [15]. The circulating fraction of these cells can be increased by process named mobilization. The pharmacological mobilization of hematopoietic stem and progenitor cells is usually obtained by using cyclophosphamide in combination with myeloid growth factors, which enhance the effect of chemotherapeutic agent $[3,5,6,16]$. Although the molecular mechanism of mobilization is widely examined, the morphology of the bone marrow and organs, which participate in hematopoiesis in mice, is poorly known. In our study, the morphology and ultrastruc- 


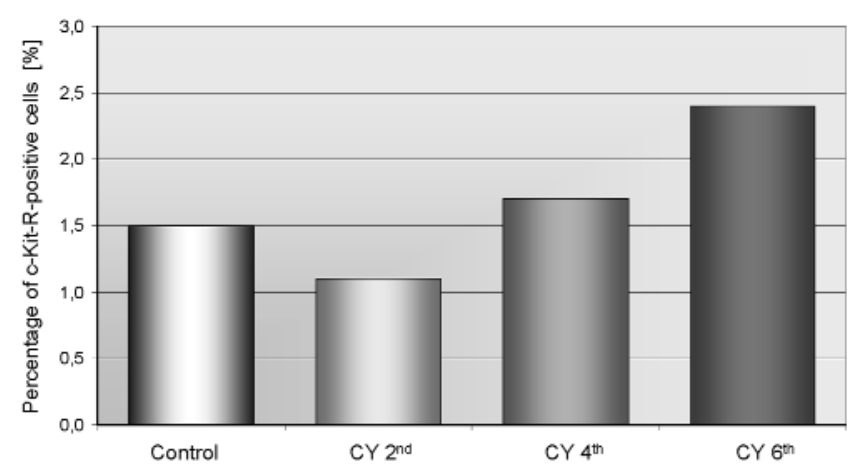

Fig. 6. Percentage of c-Kit-R-positive cells in MNC of control and experimental group of mice.

ture of the bone marrow, morphology of the spleen and liver on day 2., 4., 6. after mobilization with cyclophosphamide in murine model were examined.

It has been known that $\mathrm{CY}$ induces the BM aplasia, and we also observed typical morphological features of this process. On the $2^{\text {nd }}$ day after mobilization with single dose of $\mathrm{CY}$ we noticed destructive changes in the bone marrow [12]. The dramatic reduction in hematopoietic area and increased vascular compartment with strongly dilated sinusoids were observed as the effect of cytoreductive properties of cyclophosphamide. There were cells containing hemosiderin among the hematopoietic cells, what indicated the phagocytosis performed by stromal cells and macrophages removing the damaged cells. The erythrocytes are normally confined to the vascular space, thus their presence within the hematopoietic compartment suggested the loss of integrity of sinusoidal wall. Lack of sinusoid continuity supported the observation of penetration of macrophages into the lumen of vessel. The findings were in accordance with studies of other authors [17,18]. Additionally, we found the features of fibrosis in ultrastructure of the BM. It could be the response of stromal cells to changes of the bone marrow microenvironment and impaired interaction between bone marrow cells and extracellular matrix elements.

Myelofibrosis is common clinical feature in a variety of hematological malignancies $[19,20]$. This includes the synthesis and local collagen deposition. The molecular basis of the process is unknown but it seems to be multifactoral [21]. In vivo and in vitro studies indicate that several cytokines are involved in the development of myelofibrosis [22,23]. TGF- $\beta 1$, secreted by megakaryocytes and platelets $[24,25]$ is considered to play the crucial role in the development of myelofibrosis. This pleiotropic cytokine stimulates stromal cells of the BM to produce collagen and other extracellular matrix proteins $[22,26]$. Moreover, TGF- $\beta$ modulates extracellular matrix organization and stimulates the expression of proteases, which inhibit the enzymes involved in degradation of matrix proteins [27].
On day 4. of the experiment the proliferating cells and the increase of hematopoietic cell amount were observed within the hematopoietic compartment. It was reported by others, that CY administration led to a rapid decrease in nucleated cells number [28,29] on the 2nd day and the intensive proliferation of cells in the bone marrow on days 2-3 [29]. At that time the expression pattern of cytokine genes was changed in the bone marrow. While, the level of mRNA for TGF 1 was decreased, the levels of mRNA for SCF and SDF-1 were increased [30], what supposedly supported proliferation of the hematopoietic cells. Deposits of collagen were still observed, however its amount was diminished.

The bone marrow cellularity returned to normal values on the day 6 . of the experiment. This result was in accordance with observation of Sefc et al. [29]. The ultrastructure of the bone marrow was normal but the distances between endothelial cells of sinusoids were extended, what facilitated the departure of HSPCs from the BM. The presence of numerous nucleated cells in lumen of sinusoids visible under light microscopy may suggest that early hematopoietic cells left the bone marrow. We found, that the number of cKit-R-positive cells in the peripheral blood has peaked on the $6^{\text {th }}$ day of the experiment. The study by Craddock et al. [31] reported that peak numbers of CFU-S and CFU-GM in the peripheral blood occurred 8 days after cyclophosphamide administration. In our previous studies, the biggest pool of c-Kit-R-positive cells in the circulation was observed on the 4th day during treatment with G-CSF [10] and G-CSF plus CY [11]. Had our experiment been carried out longer, the c-KitR-positive cells would have occurred in higher percentage in following days.

The spleen of mice treated with CY revealed changes in morphology including a hyperplasia of the red pulp. The spleen in mice is an active hematopoietic organ during the ontogenesis [32]. Similarly to the bone marrow, cyclophosphamide caused cytoreductive effect in spleen. Moreover, in our observation CY produced temporary fibrosis of spleen deposits of reticulin were seen on the day 2., less visible on day 4 . and the normal amounts were observed back on day 6 . of the experiment. It was shown, that administration of CY was associated with marked cytopenia in the spleen [33] and directly induced a significant decrease in number of the myeloid progenitors [34]. On day 4., we observed the reduction of spleen mass, what was in accordance with the discovery by Karp \& Szczytkowski [35]. This effect can be related to severe leukopenia, with was deepest on day 4. after injection with CY, as reported by Shalit et al. [34]. The increase of the amount of the cells between day 4. and 6 . can be explained in two ways: the proliferation of cells in the spleen and the transfer of hematopoietic stem and pro- 
genitor cells from the bone marrow. During mobilization of mice with CY, the pattern of hematopoietic cytokine expressions in spleen was changed, as it was seen in the BM. The level of SCF mRNA was about 50 -fold higher in the spleen when compared to the bone marrow [29]. It was shown, that the CFU-S doubling time in the spleen was $4.4 \mathrm{~h}$ between days 4 and 5 after administration of cyclophosphamide, thus it would not be able to significantly contribute to the obtained results by proliferation and self-reproduction of cells alone. Therefore a significant migration of progenitors from the bone marrow to the spleen has been expected to be responsible for the observed effects [29].

On the day 6 . the cellularity in the spleens of experimental mice appeared to be similar to the spleens of control mice, and the number of proliferating cells observed in the spleen was decreased. As it was reported, the CFU-S proliferation rate in spleen decreased on days 8. and 9. after CY mobilization [29], and our previous study presented the decrease in the proliferating cells number in spleen on day 6. after G-CSF plus CY treatment [11]. There were no features of fibrosis in the spleens of experimental mice on day 6 . The mechanism of the spleen fibrosis is the same as in the BM and it is related to the increase in TGF- $\beta 1$, produced by megakaryocytes. The densification of the reticulin network was observed in the spleens of mice with thrombopoietin overexpression $[22,36]$.

There were no marked morphological changes in the livers of experimental mice. Although cyclophosphamide is regarded to be a hepatotoxic agent, the hepatocytes' morphology observed in light microscopy was not altered. However, Malhi et al. [37] showed in electron microscopy experiments the endothelial injury just within 6 hours after CY treatment and the endothelium disorganization in most sinusoids was observed after 24 and 48 hours. In their studies, CY had no obvious effects on hepatocytes and Kupffers' cells [37]. In our experiment, we observed the increase in number of Kupffers' cells in zone III (central venous drainage) and zone II (intermediate region) on day 6 . after CY administration. Hyperplasia of Kupffers' cells can reflect the activity of hepatic lymphoid tissue. Alongside with hepatic macrophages, the liver contains other components of lymphoid tissue such as $\mathrm{T}$ lymphocytes, B cells, NK cells [38]. In response to toxic factors, the hyperplasia of lymphoid tissue components can be observed. The localization and shape of Thy-1- or c-Kit-R-positive cells in liver of mice were the same as in our earlier study [11].

Finally, we conclude that mobilization HSPC with cyclophosphamide alone in mice results in the aplasia of the BM with features of myelofibrosis and morphological alteration of the spleen and no pronounced changes in the liver, as examined under light micro- scope. The beginning of the recovery of the BM ultrastructure was observed on the $6^{\text {th }}$ day after CY injection. The egress of HSPC from the BM was also observed on the 6th day, and it was the time of repopulation of spleen with these cells. However, the release of HSPC from the bone marrow into the peripheral blood was delayed as compared to mice treated with G-CSF or GCS-F plus CY.

\section{References}

[1] Neben S, Marcus K, Mauch P. Mobilization of hematopoietic stem and progenitor cell subpopulations from the marrow to the blood of mice following cyclophosphamide and/or granulocyte colony stimulating factor. Blood. 1993;81:960-1967.

[2] Schwartzberg LS, Birch R, Hazelton B, Tauer KW, Lee P Jr, Altemose R, George C, Blanco R, Wittlin F, Cohen J, Muscato I, West WH. Peripheral blood stem cell mobilization by chemotherapy with and without recombinant human granulocyte colony stimulating factor. J Hematother. 1992;1:317-327.

[3] Levesque JP, Hendy J, Takamatsu Y, Wiliams B, Winkler IG, Simmons PJ. Mobilization by either cyclophosphamide or granulocyte colony stimulating factor transforms the bone marrow into a highly proteolytic environment. Exp Hematol. 2002;30:440-449.

[4] Lapidot T, Petit I. Current understanding of stem cell mobilization: the roles of chemokines, proteolytic enzymes, adhesion molecules, cytokines, and stromal cells. Exp Hematol. 2002;30,973.

[ 5] Levesque JP, Hendy J, Takamatsu Y, Simmons PJ, Bendall LJ. Disruption of the CXCR4/CXCL12 chemotactic interaction during hematopoietic stem cell mobilization induced by GCSF or cyclophosphamide. J Clin Invest. 2003;111:187-196.

[6] Levesque JP, Winkler IG, Hendy J, Williams B, Helwani F, Barbier V, Nowlan B, Nilsson SK. Hematopoietic progenitor cell mobilization results in hypoxia with increased Hypoxiainducible Transcription Factor-1 and Vascular Endothelial Growth Factor A in bone marrow. Stem Cells. 2007;25:19541965.

[ 7] Thomas J, Liu F, Link DC. Mechanisms of mobilization of hematopoietic progenitors with granulocyte colony stimulating factor. Curr Opin Hematol. 2002;9:183-189.

[ 8] Reca R, Cramer D, Yan J, Laughlin MJ, Janowska-Wieczorek A, Ratajczak J, Ratajczak MZ. A novel role of complement in mobilization: immunodeficient mice are poor granulocytecolony stimulating factor mobilizers because they lack complement-activating immunoglobulins. Stem Cells. 2007;25: 3093-3100.

[ 9] Barcew K, Kacińska E, Marchlewicz M, Wiszniewska B, Machaliński B. Bone marrow morphology during heamtopoietic stem cell mobilization with G-CSF in mice. Folia Morphol. 2004;63:87-89.

[10] Barcew K, Paczkowska E, Dąbkowska E, BaśkiewiczMasiuk M, Marchlewicz M, Domański L, Sagan L, Wiszniewska B, Machaliński B. The effect of stem cell mobilisation with granulocyte colony-stimulating factor on the morphology of the haematopoietic organs in mice. Folia Morphol. 2007;66:1-9.

[11] Szumilas P, Barcew K, Baśkiewicz-Masiuk M, Wiszniewska B, Ratajczak MZ, Machaliński B. Effect of stem cell mobilization with cyclophosphamide plus granulocyte colonystimulating factor on morphology of haematopoietic organs in mice. Cell Prolif. 2005;38:47-61.

[12] Karbicka A, Marchlewicz M, Wiszniewska B, Machalinski B. Bone marrow morphology during haematopoietic stem cell 
mobilization with cyclophosphamide in mice. Folia Morphol. 2003;62,435-437.

[13] Bancroft JD, Gamble M. Theory and practice of histological techniques. London; Churchil Livingstone, 2002;75,217.

[14] Janowska-Wieczorek A, Majka M, Kijowski J, Baj-Krzyworzeka M, Reca R, Turner AR, Ratajczak J, Emmerson SG, Kowalska MA, Ratajczak MZ. Platelet-derived microparticles bind to hematopoietic stem/progenitor cells and enhance their engraftment. Blood. 2001;98:3143-3149.

[15] Papayannopoulou T. Current mechanistic scenarios in hematopoietic stem/progenitor cell mobilization. Blood. 2004;103:1580-1585.

[16] Caporali R, Perotti C, Pedrazozoli P, De Prada GA, Bernuzzi $\mathrm{S}$, Montecucco C. Cyclophosphamide plus granulocyte colony stimulating factor (G-CSF) is more effective than GCSF alone in mobilizing hematopoietic progenitor cells in severe, refractory rheumatoid arthritis. Haematologica. 2001; 86:106-107

[17] Anton E. Ultrastructural changes of stroma cells on bone marrow and liver after cyclophosphamide treatment in mice. Tissue Cell. 1997;29:1-9.

[18] Shirota T, Tavassoli M. Cyclophosphamide-induced alterations of bone marrow endothelium: implications in homing of marrow cells after transplantation. Exp Hematol. 1991;19: 369-373.

[19] Abe Y, Ohshima K, Shiratsuchi M, Honda K, Nishimura J, Nawata H, Muta K. Cytotoxic T-cell lymphoma presenting secondary myelofibrosis with high levels of PDGF and TGF- $\beta$. Eur J Haematol. 2001;66:210-212.

[20] Burthem J, Cawley JC. The bone marrow fibrosis of hairycell leukemia is caused by the synthesis and assembly of a fibronectin matrix by the hairy cells. Blood. 1994;83:497-504.

[21] Shivdasani R. An animal model for myelofibrosis. Blood. 2002; 100:1109.

[22] Chagraoui H, Komura E, Tulliez M, Girauder S, Vainchenker $\mathrm{W}$, Wendling F. Prominent role of TGF- $\beta 1$ in thrombopoietininduced myelofibrosis in mice. Blood. 2002;100:3495-3503.

[23] Le Bousse-Kerdiles MC, Martyre M. Dual implication of fibrogenic cytokines in the pathogenesis of fibrosis and myeloproliferation in myeloid metaplasia with myelofibrosis. Ann Hematol. 1999;78:437-444.

[24] Castro-Malaspina H. Pathogenesis of myelofibrosis: role of ineffective megakaryopoiesis and megakaryocyte components. Prog Clin Biol Res. 1984;154:427-454.

[25] Terui T, Niitsu Y, Mahara K, Fujisaki Y, Urushizaki Y, Mogi Y, Kohgo K, Watanabe N, Ogura M, Saito H. The production of transforming growth factor-beta in acute megakaryoblastic leukemia and its possible implications in myelofibrosis. Blood. 1990;75:1540-1548

[26] Kimura A, Kotoh O, Hyodo H, Kuramoto A. Tranforming growth factor- $\beta$ regulates growth as well as collagen and fibronectin synthesis of human marrow fibroblasts. $\mathrm{Br} \mathrm{J} \mathrm{Hae-}$ matol. 1989;72:486-491.

[27] Mervin J, Anderson J, Kocher O, van Italie C, Madri J. Transforming growth factor- modulates extracellular matrix organization and cell-cell junctional complex formation during in vitro angiogenesis. J Cell Physiol. 1990;142:117-128.

[28] Aguirre MV, Juaristi JA, Alba Alvarez M, Carmuega RJ, Brandan NC. In vitro and in vivo studies of murine erythropoietic recovery after treatment with cyclophosphamide. Sangre (Barcelona). 1999;44:182-187.

[29] Sefc L, Psenak O, Sykora V, Sulc K, Necas E. Response of hematopoiesis to cyclophosphamide follows highly specific patterns in bone marrow in spleen. $J$ Hematother Stem Cell Res. 2003;12:47-61.

[30] Psenak O, Sefc L, Sykora V, Chang KT, Necas E. Cytokine gene expression in regenerating haematopoietic tissue of mice after cyclophosphamide treatment. Acta Haematol. 2003; 109:68-75.

[31] Craddock CF, Apperley JF, Wright EG, Healy LE, Bennett CA, Evans M, Grimsley PG, Gordon MY. Circulating stem cells in mice treated with cyclophosphamide. Blood. 1992; 80:264-269.

[32] Yoder MC. Embryonic hematopoiesis in mice and humans. Acta Paediatr Suppl. 2002;91(438):5-8.

[33] Verma UN, van den Blink Pillai R, Chawla J, Mazumder A, Herscowith HB, Meehan KR. Paclitaxel vs cyclophosphamide in peripheral blood stem cell mobilization: comparative studies in a murine model. Exp Hematol. 1999;27:553560.

[34] Shalit I, Kletter Y, Halperin D, Waldman D, Vasserman E, Nagler A, Fabian I. Immunomodulatory effects of moxifloxacin in comparison to ciprofloxacin and G-CSF in murine model of cyclophosphamide-induced leukopenia. Eur J Haematol. 2001;66:287-296.

[35] Karp JD, Szczytkowski JL. Cyclophosphamide induces doseand time-dependent elevation spleen norepinephrine levels of BALB/c mice. Neurosci Lett. 2003;344:117-121.

[36] Chagraoui H, Tulliez M, Smayra T, Komura E, Girauder S, Yun T, Lassau N, Vainchenker W, Wendling F. Stimulation of osteoprotegerin production is responsible for osteosclerosis in mice overexpressing TPO. Blood. 2003;101:2983-2989.

[37] Malhi H, Annamaneni P, Slehria S, Joseph B, Bhargava KK, Palestro CJ, Novikoff PM, Gupta S. Cyclophosphamide disrupt hepatic sinusoidal endothelium and improves transplanted cell engraftment in rat liver. Hepatology. 2002;36:112-121.

[38] Golden-Mason L, O'Farrelly C. Having it all? Stem cells, haematopoiesis and lymphopoiesis in adult human liver. Immunol Cell Biol. 2002;80:45-51.

Submitted: 15 April, 2008 Accepted after reviews: 21 July, 2008 